\title{
Performance evaluation of low-cost IoT based chlorophyll meter
}

\author{
Heri Andrianto ${ }^{1}$, Suhardi ${ }^{2}$, Ahmad Faizal ${ }^{3}$ \\ ${ }^{1,2}$ School of Electrical Engineering and Informatics, Institut Teknologi Bandung, Indonesia \\ ${ }^{3}$ School of Life Sciences and Technology, Institut Teknologi Bandung, Indonesia
}

\section{Article Info \\ Article history: \\ Received Aug 4, 2019 \\ Revised Oct 23, 2019 \\ Accepted Feb 4, 2020}

\section{Keywords:}

Chlorophyll meter Internet of Things (IoT)

Plant nutritional deficiencies

\begin{abstract}
Nutrient deficiencies in plants can be identified using a chlorophyll meter. However, current chlorophyll meters are still expensive and have many disadvantages. In this paper, a low-cost IoT-based chlorophyll meter has been developed. The performance of a low-cost IoT-based chlorophyll meter has been compared with the performance of a spectrophotometer (SP-3000nano) and a commercial chlorophyll meter (SPAD-502). A low-cost IoT-based chlorophyll meter has been functioning properly which is able to measure the chlorophyll content of plants in the field, get positions based on GPS satellites, store data in a memory module, and send data to the service system platform. The test results showed the coefficient of determination $\left(\mathrm{R}^{2}\right)$ between SPAD-502 values and low-cost IoT-based chlorophyll meter values is 0.9705 , this shows a significant correlation. An IoT-based chlorophyll meter can be used as a cheap alternative to the SPAD-502 chlorophyll meter.
\end{abstract}

This is an open access article under the $\underline{C C B Y-S A}$ license.

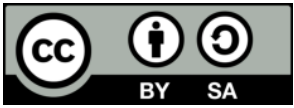

Corresponding Author:

Heri Andrianto,

School of Electrical Engineering and Informatics,

Institut Teknologi Bandung,

Jl. Ganesha No.10, Bandung, Indonesia.

Email: heri.andrianto@students.itb.ac.id

\section{INTRODUCTION}

Communication and information technology will facilitate farmers to explore innovative ways to minimize risks and to increase production [1]. Recently, Internet of Things (IoT) as one part of communication and information technology is developing rapidly and has been widely applied in various fields, such as in agriculture. The IoT is a combination of all the "things" by using the internet as the backbone of a communication system to build intelligent interactions between people and objects around them $[2,3]$. Most IoT technology solutions in the field of agro-industry and the environment focus on monitoring (62\%), controls (25\%), logistics (7\%), and predictions (6\%) [4]

In field of agriculture, the nitrogen content in the soil can be determined through the chlorophyll content of plant leaves, because nitrogen content is strongly related to chlorophyll content $[5,6]$. Sensor technology can be used to detect the chlorophyll content of plant leaves based on the ability of the leaves to absorb, transmit and reflect light [7]. This technology has been applied to spectrophotometer $[8,9]$ and chlorophyll meter [10-14]. Spectrophotometer can be used to analyze chlorophyll pigments in extracted plant leaves, but this method has disadvantages such as destructive, tiring and time consuming [13]. This device is not only expensive but also has a large size therefore it is only used in laboratories. Meanwhile, between fields and the laboratories are generally separated by long distances [15]. Therefore, carrying the leaves of plants from field to the laboratory becomes ineffective and inefficient. 
A chlorophyll meter allows non-destructive measurement of chlorophyll content in the field, however chlorophyll meters available on the market are still expensive. Van Den Berg and Perkins [16] have reported that a portable chlorophyll meter (CCM-200) is an effective, rapid, and non-destructive devices for estimating the chlorophyll content in sugar maple leaves during the growing season. Another chlorophyll meter is SPAD-502, it is the most widely used chlorophyll meter [7]. Several studies have been conducted to measure the chlorophyll content of various plants using SPAD-502 [10, 17-21]. The chlorophyll content in leaves is expressed in Chlorophyll Content Index (CCI) unit or Soil Plant Analysis Development (SPAD) unit. Chlorophyll content of plant leaves in the CCI unit is calculated using [22]:

$$
\mathrm{CCI}=\frac{\% \text { transmission IR }}{\% \text { transmission RED }}
$$

Conversion from CCI to SPAD is calculated using [22]:

$$
\mathrm{SPAD}=\mathrm{k} \log (\mathrm{CCI})+\mathrm{c}
$$

Where:

k: Confidential slope coefficient

c: Confidential offset value

As an example, computational processes for calculating the amount of Nitrogen $(\mathrm{N})$ fertilizer that must be given to plants (corn and wheat) consists of calculating the average value of chlorophyll content from the field and calculating chlorophyll content from the reference area where $\mathrm{N}$ levels are high. $\mathrm{N}$ recommendation for plants (corn and wheat) is calculated using [23-25]:

$$
\mathrm{N}=6+(7 \times \mathrm{D})
$$

Where:

$\mathrm{N}=\mathrm{N}(\mathrm{lb} / \mathrm{A})$ needed at Feekes 5 for optimal growth

$\mathrm{D}=$ The difference between the average chlorophyll measurements from the agricultural land and the reference areas that have high $\mathrm{N}$ levels (in a SPAD unit)

\section{RELATED WORKS}

Several studies on the design and realization of a low-cost chlorophyll meter have been carried out. Takeuchi et al [26] reported the development of a simple PAM chlorophyll fluorometer for monitoring vegetation conditions using a Programmable Logic Controller (PLC) and a computer. Maleki et al [27] reported the development of a device to measure nitrogen content in lettuce plants using the TCS230 sensor. Lamb et al [28] reported the development of a fluorometers based on LED for quantification of chlorophy ll in the field and in the laboratory. Sookchalearn and Abdullakasim [29] reported the development of a tool to measure the chlorophyll content of cassava plants using TCS230 sensor and added a Global Position System (GPS) module to get a location when measuring chlorophyll content of plant leaves in the field. Limitations of previous studies, namely requires expensive costs [26], destructive [28], no data sending facility to the server for agricultural data management [26-29], no data storage facility in non volatile memory therefore data will be lost if the power is turned off [26-29], no data location based on GPS satellites [26-28], and no interface to external devices [26-28].

New innovations are needed on chlorophyll meter devices to meet user need s and provide solutions to the current limitations of chlorophyll meters, namely by applying IoT technology, storage facility, location based on GPS satellites and data sending facility to the service system platform for agricultural data management. This study is primarily interested in design and realization of a low-cost IoT-based chlorophyll meter for collecting chlorophyll content and location data from the field and send it to the service system platform. The performance of a low-cost IoT-based chlorophyll meter is also compared to more expensive chlorophyll meter (SPAD-502) and spectrophotometer(SP-3000nano).

\section{RESEARCH METHOD}

The research method consists of four stages, namely designing IoT-based service system architecture for monitoring plant nutrition deficiencies (Figure 1), developing low cost IoT-based chlorophyll meter, testing the low cost IoT-based chlorophyll meter and evaluating the performance of a low cost 
IoT-based chlorophyll meter. The first stage is designing IoT-based service system architecture for monitoring plant nutrition deficiencies. The IoT-based service system architecture for monitoring plant nutrition deficiencies consists of IoT-based chlorophyll meters, wireless access points, service system platforms and remote monitoring devices. In this system, farmers can measure the chlorophyll content of plant leaves, mark a location based on GPS satellites at the time of measurement in the field and send data to the service system platform using an IoT-based chlorophyll meter. The low-cost IoT-based chlorophyll meter uses the API Key as an ID to enter and communicate with the service system platform. This system can be used for effective and efficient agriculture because it only requires one IoT-based chlorophyll meter device to collect data rather than installing multiple sensors in the field, such as in the Wireless Sensor Network system(WSN) [30-31].

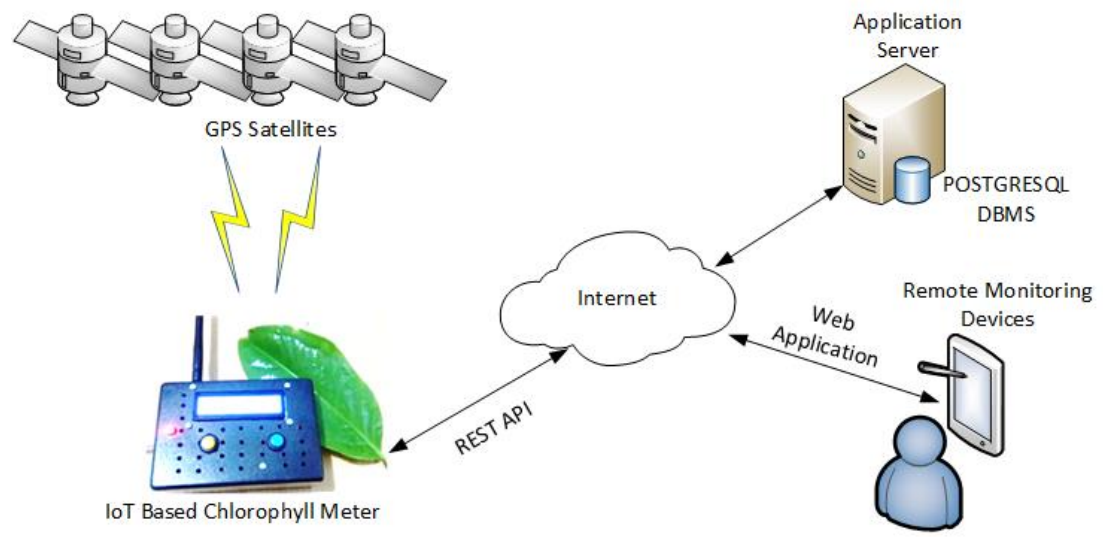

Figure 1. An IoT-based service systemarchitecture for monitoring plant nutrition deficiencies

\subsection{Developing a low-cost IoT-based chlorophyll meter}

The second stage is developing a low cost IoT-based chlorophyll meter. Low cost IoT based chlorophyll meter devices consist of NodeMCU, red and infrared LEDs, spectral sensor (TSL2561), GPS module (GPS6MV2), LCD module, pushbutton, and memory module. Table 1 shows connection of NodeMCU pins with other components. Figure 2 shows an IoT based chlorophyll meter device that has been developed.

Table 1. Connection of NodeMCU pins with other components

\begin{tabular}{cccccc}
\hline NodeMCUPins & LCD Module & TSL2561 Sensor & Memory Module & GPS6MV2 & PushButton \\
\hline D0 & SCL & SCL & & \\
D1 & SDA & SDA & & \\
D2 & & & SCK & \\
D5 & & MISO & & \\
D6 & & MOSI & & \\
D7 & & CS & TX & \\
D8 & & & RX & \\
D9 & & & & \\
D10 & & & & \\
\hline
\end{tabular}

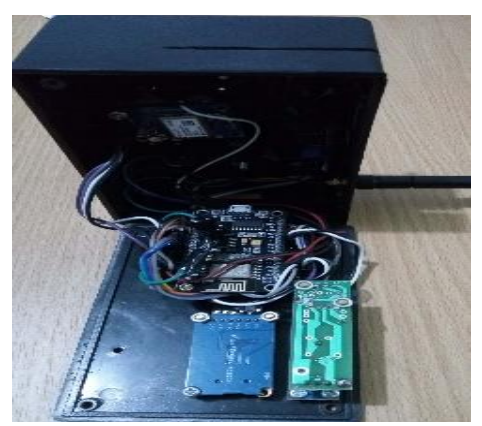

Figure 2. IoT based chlorophyll meter realization 


\subsection{IoT-based chlorophyll meter flowchart}

Main program flowchart (Figure 3), starting with the process of initializing the components, then selecting the online or offline mode. If offline mode is selected, then the data will be stored in the memory module when the button is pressed. If online mode is selected, then the data will be sent to the database server when the button is pressed. Sub program flowchart (Figure 4) to obtain chlorophyll content and location based on GPS satellites starting with the process of obtaining positions based on GPS satellites (Long and Lat), reading the intensity of red and infrared light transmitted by the leaf on the spectral sensor, and calculating the CCI values. Finaly, CCI, Long and Lat are displayed on the LCD.

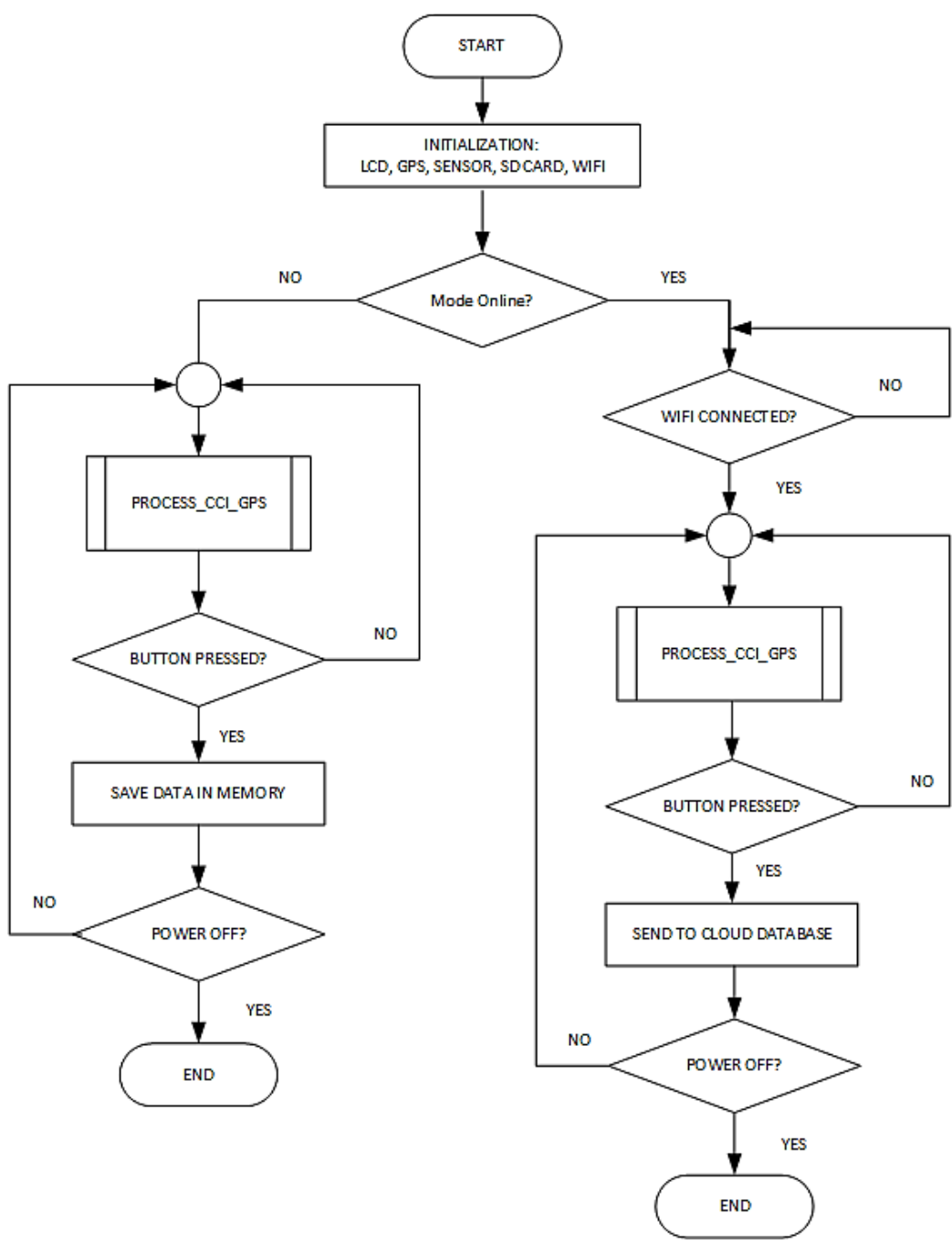

Figure 3. Flowchart of main program

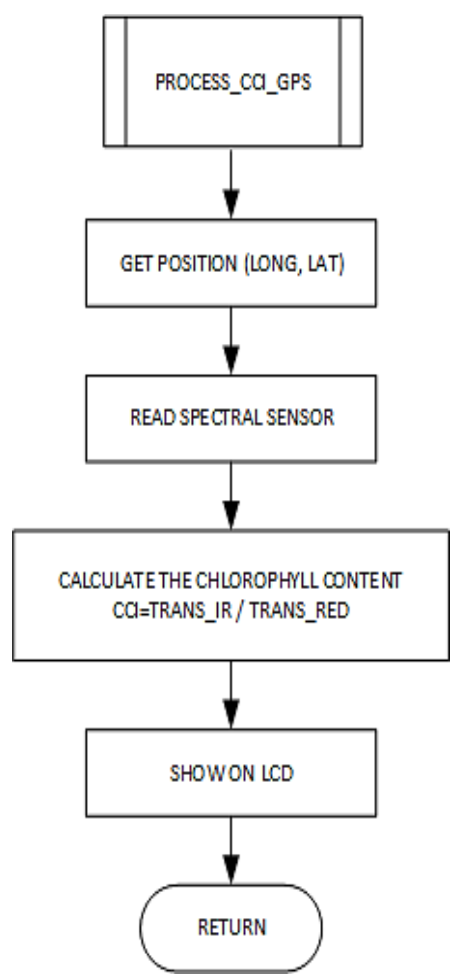

Figure 4. Flowchart of process $\mathrm{CCI}$ and GPS

\section{RESULTS AND DISCUSSION}

A low-cost IoT-based chlorophyll meter testing has been conducted by comparing the performance of a low-cost IoT-based chlorophyll meter with a chlorophyll meter (SPAD-502) and a spectrophotometer (SP-3000nano). Measurements of chlorophyll content were conducted on the leaves of maniltoa grandiflora (young leaves, adult leaves and old leaves). The leaf chlorophyll content was measured using a low-cost IoT-based chlorophyll meter and a SPAD-502 at four different positions (Figure 5) and repeated five times which were then taken the average value. We have also measured the leaf chlorophyll content using a spectrophotometer (Figure 6). As shown in Figure 7 to Figure 9, the measuring chlorophyll content results using a spectrophotometer, a SPAD-502 and a low-cost IoT-based chlorophyll meter are strongly correlated. It can be concluded that young leaves have less chlorophyll content than mature leaves and old leaves. The leaves that contain the most chlorophyll are old leaves. As chlorophyll is linearly correlated with 
nitrogen, young leaves have less nitrogen content than mature leaves and old leaves. Young leaves need more nitrogen than mature leaves and old leaves.

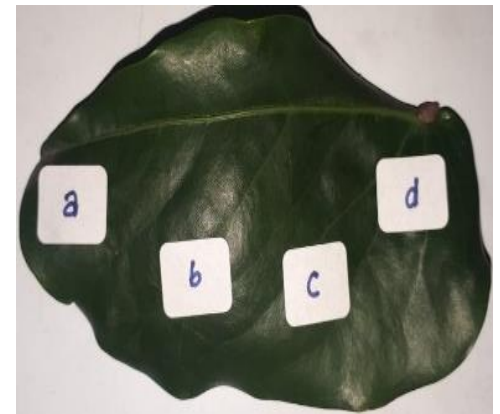

Figure 5. Measurement of chlorophyll content in four positions

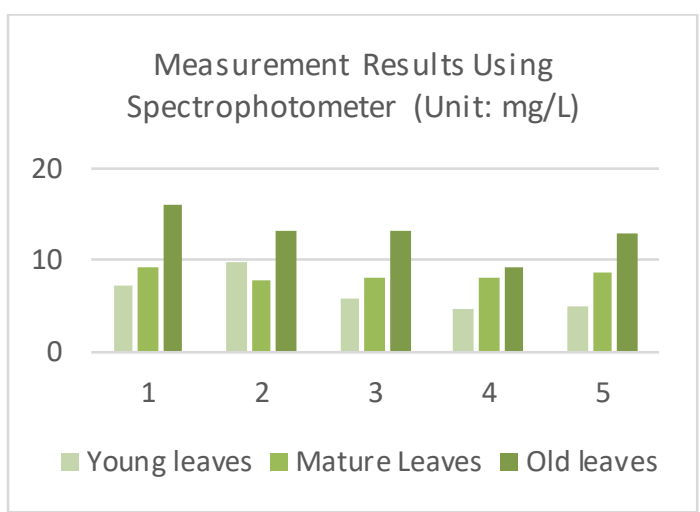

Figure 7. Measurement of chlorophyll content using Spectrophotometer

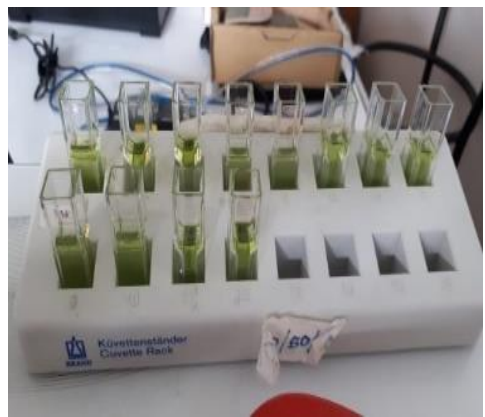

Figure 6. Measurement of chlorophyll content through Leaf extract

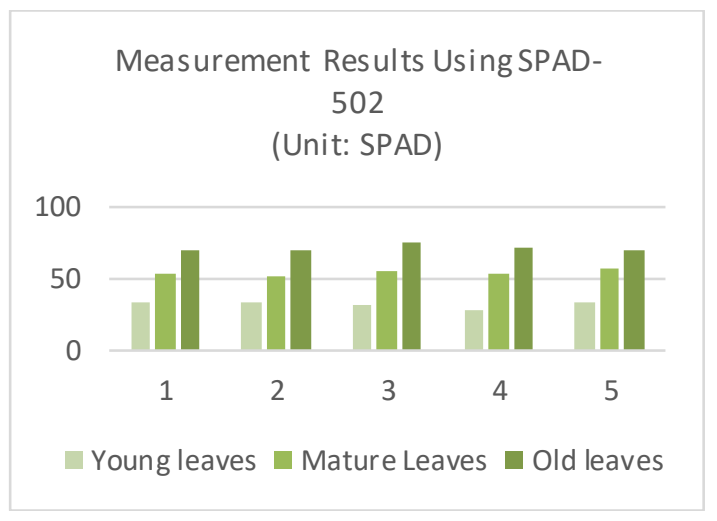

Figure 8. Measurement of chlorophyll content using SPAD-502

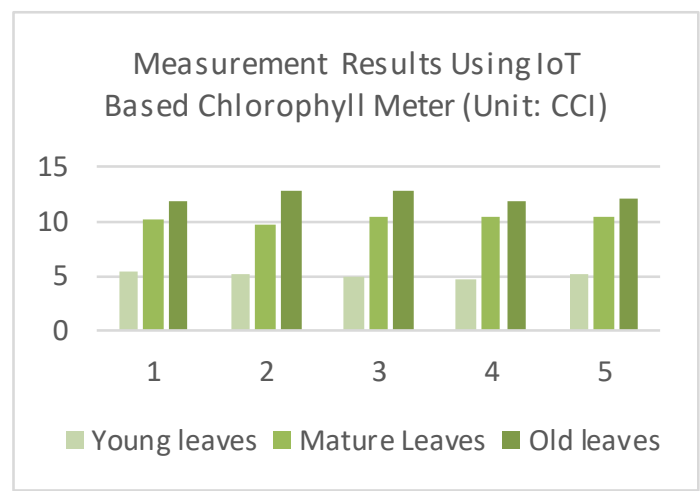

Figure 9. Measurement of chlorophyll content using low-cost IoT-based chlorophyll meter

The strength of the correlation between chlorophyll content measurement using a low-cost IoT-based chlorophyll meter and a SPAD-502 is assessed using the coefficient of determination $\left(\mathrm{R}^{2}\right)$. From the test results, we obtained an $\mathrm{R}^{2}$ of 0.9705 (Figure 10), this shows a very strong correlation between low-cost IoT-based chlorophyll meter values and SPAD-502 values. A low-cost IoT-based chlorophyll meter has been used successfully to measure chlorophyll content, these results in accordance with other reports $[13,27,29,32]$. 


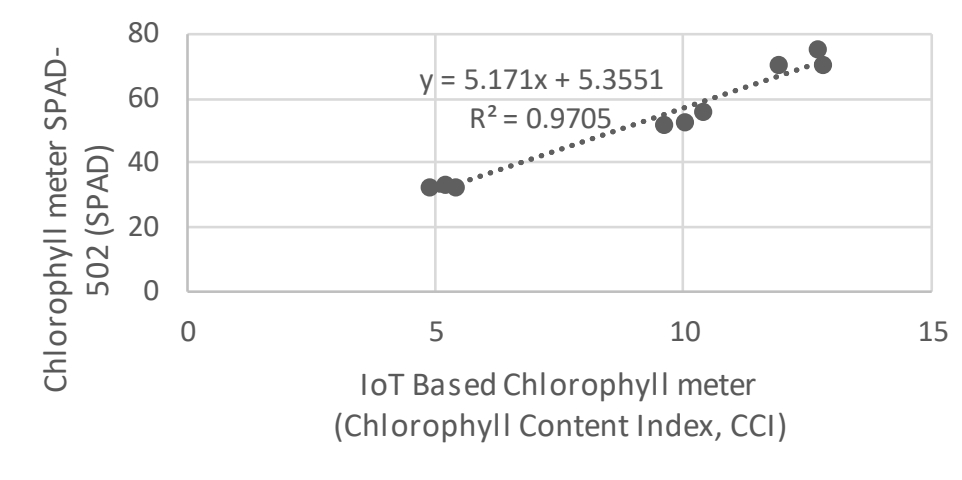

Figure 10. Correlations between SPAD values and IoT-based Chlorophyll meter in the leaves of maniltoa grandiflora

Testing of a sensor module, a memory module, and an LCD module is conducted by inserting leaf in a low-cost IoT-based chlorophyll meter and pressing a button to save data into memory and send data to the server. Test results show the device has worked well, chlorophyll content of plant leaves and location based on GPS satellites can be displayed on the LCD, stored in memory and sent to the server. Figure 11 shows the data displayed on the LCD and data in the form of text files stored in memory.

\begin{tabular}{|c|c|}
\hline 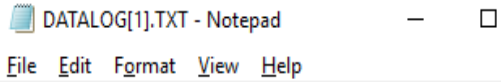 & $X$ \\
\hline $\begin{array}{l}\text { CCI }=1.00 \text {, Lat }=-6.941447, \text { Lon }=107.558739 \\
C C I=7.34 \text {, Lat }=-6.941450, \text { Lon }=107.558754 \\
C C I=8.61 \text {, Lat }=-6.941441 \text {, Lon }=107.558754 \\
C C I=9.29 \text {, Lat }=-6.941441 \text {, Lon }=107.558754 \\
C C I=21.37 \text {, Lat }=-6.941446, \text { Lon }=107.558754 \\
C C I=19.20 \text {, Lat }=-6.941449, \text { Lon }=107.558754 \\
C C I=19.24 \text {, Lat }=-6.941449, \text { Lon }=107.558746 \\
C C I=19.72 \text {, Lat }=-6.941449, \text { Lon }=107.558746 \\
C C I=14.28 \text {, Lat }=-6.941450, \text { Lon }=107.558754\end{array}$ & $\wedge$ \\
\hline & \\
\hline
\end{tabular}

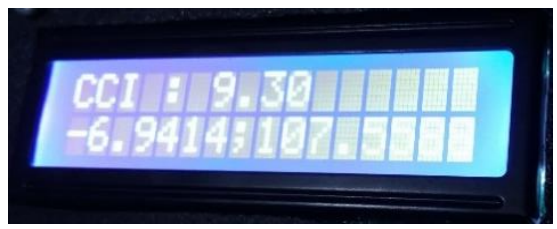

Figure 11. Memory module and LCD test results

Testing of communication between IoT-based chlorophyll meter device and service system platforms has been conducted by sending chlorophyll content and location based on GPS satellites data from a low-cost IoT-based chlorophyll meter to the service system platform. Figure 12 shows data received by the service systemplatform is displayed on monitor page (http://e-agriculture.net/).

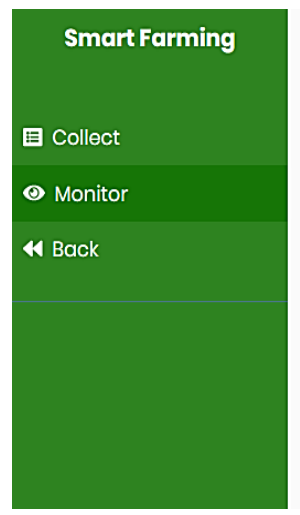

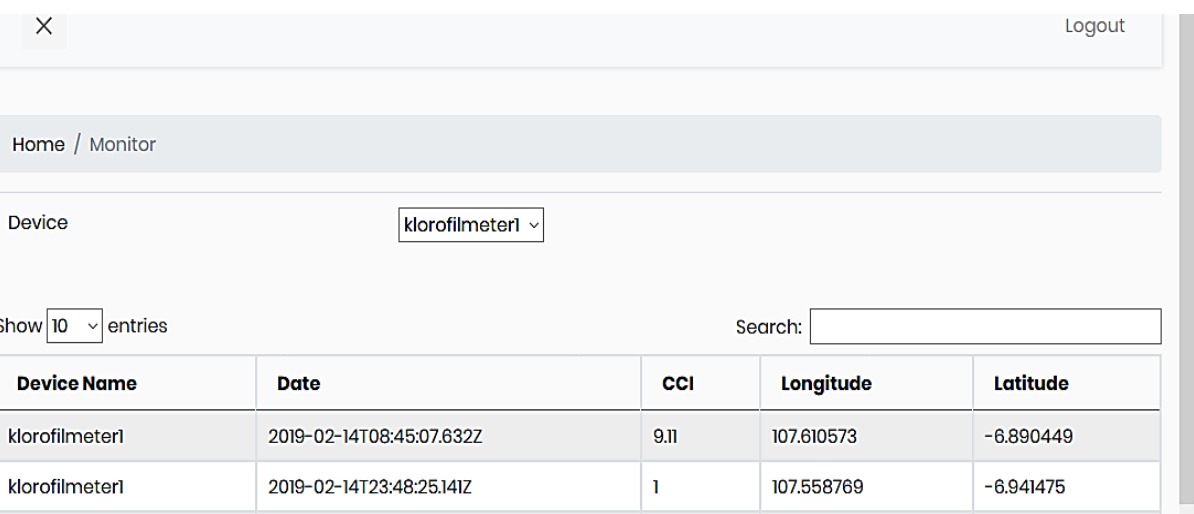

Figure 12. Data from a low-cost IoT-based chlorophyll meter is displayed on the monitor page 


\section{CONCLUSION}

The results have shown that low-cost IoT-based chlorophyll meter are functioning properly, which is able to measure chlorophyll content, get location, display data on the LCD, store data in memory, and send data to the service system platform. A strong correlation was obtained between measurements of chlorophyll content using IoT-based chlorophyll meters, SPAD-502 and spectrophotometer. The test results showed a significant relationship between SPAD-502 values and low-cost IoT-based chlorophyll meter values. Therefore, IoT-based chlorophyll meter can be used as a cheap alternative to SPAD-502 chlorophyll meter. In our future work, the data collected in the database server will be processed for the purpose of providing fertilizer recommendations to plants. In addition, the performance of a service system platform to monitor the chlorophyll content of plants (http://e-agriculture.net/) will be evaluated.

\section{ACKNOWLEDGEMENTS}

Authors would like to thank Institut Teknologi Bandung for the financial support that has been provided (Grants No. 684b/I1. B04.2/SK/2018). Thanks also to Universitas Kristen Maranatha for funding scholarships.

\section{REFERENCES}

[1] I. Dumitrache et al., "A cyber physical systems approach for agricultural enterprise and sustainable agriculture," 21st International Conference on Control Systems and Computer Science, pp. 477-484, 2017.

[2] Ray. P. P., "A survey of IoT cloud platforms," Future Computing and Informatics Journal, vol. 1, no. 1-2, pp. 35-46, 2016.

[3] Alsahib. S, Aldeen. Y. A, and Qureshi. K. N., "New trends in internet of things, applications, challenges, and solutions," TELKOMNIKA Telecommunication Computing Electronics and Control, vol. 16, no. 3, pp. 1114-1119, 2018.

[4] Martín. J, et al., "Review of IoT applications in agro-industrial and environmental fields," Computer and Electronics in Agriculture, vol. 142, no. 118, pp. 283-297, 2017.

[5] B. Bojović, and A. Marković. "Correlation between nitrogen and chlorophyll content in wheat (Triticum aestivum L.), Kragujevac Journal of Science, vol. 31, pp. 69-74, 2009.

[6] Andrianto. H, Suhardi, and Faizal. A., "Measurement of chlorophyll content to determine nutrition deficiency in plants: A systematic literature review," Int. Conf. on Information Technology Systems and Innovation, pp. 392-397, 2017.

[7] Andrianto. H, Suhardi, and Faizal. A., "Detection of chlorophyll content based on spectral properties at leaf level: A meta-analy sis," Int. Conf. on Information Technology Systems and Innovation, pp. 364-369, 2018.

[8] Nandiyanto. A., "A simple, rapid analysis, portable, low-cost, and arduino-based spectrophotometer with white LED as a light source for analyzing solution concentration," TELKOMNIKA Telecommunication Computing Electronics and Control, vol. 16, no. 2, pp. 580-585,2018.

[9] Isaak. S, et al., "A low cost spectroscopy with raspberry-Pi for soil macronutrient monitoring," TELKOMNIKA, vol. 17 , no. 4, pp. 1867-1873, 2019.

[10] Mielke. M. S, Schaffer. B, and Li. C, "Use of a SPAD Meter to Estimate Chlorophyll Content in Eugenia Uniflora L," Leaves as Affected by Contrasting Light Environments and Soil Flooding, Photosynthetica, vol. 48, no. 3, pp. 332-333, 2010.

[11] Cerovic. Z. G, et al., "A new optical leaf-clip meter for simultaneous non-destructive assessment of leaf chlorophyll and epidermal flavonoids," Physiologia Plantarum, vol. 146, pp. 251-260, 2012.

[12] Kumar. A, Sharma. M, and Meshram. M. R. "An analysis of leaf chlorophyll measurement method using chlorophyll meter and image processing technique," Procedia Computer Science, vol. 85, pp. 286-292, 2016.

[13] Novichonok. E. V, et al., "Use of the atLEAF + chlorophyll meter for a nondestructive estimate of chlorophyll content," Photosynthetica, vol. 54, no. 1, pp. 130-137, 2016,

[14] Padilla. F. M, et al., "Derivation of sufficiency values of a chlorophyll meter to estimate cucumber nitrogen status and yield," Computers and Electronics in Agriculture, vol. 141, pp. 54-64, 2017.

[15] Murakami.Y., "iFarm: Development of Web-based system of cultivation and cost management for agriculture," Eighth International Conference on Complex, Intelligent and Software Intensive Systems, pp. 624-627, 2014.

[16] Van Den Berg. A. K, and Perkins. T. D., "Evaluation of a portable chlorophyll meter to estimate chlorophyll and nitrogen contents in sugar maple (Acer saccharum Marsh.) leaves," Forest Ecology and Management. vol. 200, no. 1-3, pp. 113-117, 2004.

[17] Shafiq. M., et al., "Analy sis of near-infrared ( NIR ) spectroscopy for chlorophyll prediction in oil palm leaves," Bulletin of Electrical Engineering and Informatics, vol. 8, no. 2, pp. 506-513., 2019.

[18] Uddling. J. et al., "Evaluating the Relationship between leaf chlorophyll concentration and SPAD-502 chlorophyll meter readings," Photosynthesis Research., vol. 91, no. 1, pp. 37-46, 2017.

[19] Anand. M H, and Byju. G., "Chlorophyll meter and leaf colour chart to estimate chlorophyll content, leaf colour, and yield of Cassava, vol. 46, no. 4, pp. 511-516, 2008.

[20] Ling. Q, Huang. W, and Jarvis P. "Use of a SPAD-502 Meter to Measure Leaf Chlorophyll Concentration in Arabidopsis Thaliana, "Photosynthesis Research, vol. 107, no. 2,pp. 209-214, 2011.

[21] Coste. S, et al., "Assessing foliar chlorophyll contents with the SPAD-502 chlorophyll meter: A calibration test with thirteen tree species of tropical rainforest in french guiana," Annals of Forest Science, vol. 67. no. 6, pp. 6071-6075, 2010. 
[22] Parry. C, Blonquist. J. M, and Bugbee. B., "In situ measurement of leaf chlorophyll concentration: Analy sis of the optical/absolute relationship," Plant, Cell and Environment, vol. 37, no. 11, pp. 2508-2520., 2014.

[23] Francis. D. D, and Piekielek. W. P., "Assessing Crop Nitrogen Needs with Chlorophyll Meters," Site-Specific Management Guidelines, vol. 12, pp. 1-4, 2016.

[24] Murdock. L, "Using a chlorophyll meter to make nitrogen recommendations on wheat," Cooperative Extension Service, vol. 170, pp. 1-4, 1997.

[25] Murdock. L, Call. D, and James. J., "Comparison and use of chlorophyll meters on wheat (Reflectance vs. Transmittance/Absorbance)," UK Cooperative Extension Service, vol. 181, pp. 1-4, 2004.

[26] Takeuchi. A, Yoshida. H, and Shibata. M., "Development of simplified PAM chlorophyll fluorometer for vegetation condition monitoring," International Symposium on Consumer Electronics, pp. 130-132, 2009.

[27] Maleki. M, Massah. J, and Dehghan. M., "Application of a spectral sensor for the assessment of nitrogen content in lettuce plants," Australian Journal of Crop Science, vol. 6, no. 2, pp. 188-193, 2012.

[28] Lamb. J. J, Eaton-Rye. J. J, and Hohmann-Marriott. M. F, "An LED-Based fluorometer for chlorophyll quantification in the laboratory and in the field," Photosynthesis Research, vol. 114, no. 1, pp. 59-68, 2012.

[29] Sookchalearn. T, and Abdullakasim. W, "A low-cost sensor for measuring and mapping chlorophyll content in cassava leaves," Chiang Mai University Journal of Natural Sciences., vol. 16, no. 3, pp. 183-190, 2017.

[30] Muzafarov. F, and Eshmuradov, "A. wireless sensor network based monitoring system for precision agriculture in Uzbekistan," TELKOMNIKA Telecommunication Computing Electronics and Control, vol. 17, no. 3, pp. 1071-1080,2009.

[31] Kamaruddin. F, et al, "IoT-based intelligent irrigation management and monitoring system using arduino," TELKOMNIKA Telecommunication Computing Electronics and Control, vol. 17, no. 5, pp. 2378-2388, 2019.

[32] Zhu. J, Tremblay. N, and Liang. Y, "Comparing SPAD and atLEAF values for chlorophyll assessment in crop species," Canadian Journal of Soil Science, vol. 92, no. 4, pp. 645-648, 2012.

\section{BIOGRAPHIES OF AUTHORS}
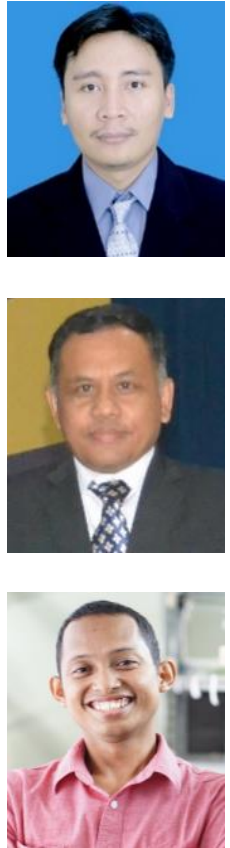

Heri Andrianto is currently a Ph.D. student in the School of Electrical Engineering and Informatics, Institut Teknologi Bandung, Indonesia. He received his bachelor's degree in electrical engineering from Universitas Kristen Maranatha, Bandung, Indonesia, in 2004, and his master's degree in information technology from Institut Teknologi Bandung (ITB), Bandung, Indonesia, in 2007. He is interested in the field of embedded system, microcontroller, service computing, and internet of things.

Suhardi received the B.E., M.E. in Electrical Engineering from Institut Teknologi Bandung (ITB), Indonesia, in 1988 and 1992, respectively. He received Doktor der Ingeneuer (Dr.-Ing.) in Electrical Engineering from Technical University of Berlin, Germany in 1997. In 1990, he joints the School of Electrical Engineering and Informatics ITB as a lecturer and affiliated with Information Technology Research Group. He is a member of IEEE. He is a professor in services computing area. His research interests are in the areas of services computing, service systems engineering, digital forensics and cyber-crime, and IT value engineering.

Ahmad Faizal received the B.Sc., M.Sc. in the School of Life Sciences and Technology, Institut Teknologi Bandung (ITB), Bandung, Indonesia, in 2004, and 2006. He obtained his PhD. in Applied Biological Sciences from Ghent University, Belgium in 2013. Currently, he is a faculty member of School of Life Sciences and Technology ITB. He is interested in the field of plant sciences and biotechnology. 